\title{
Efficacy And Safety Of Adalimumab Biosimilar (Exemptia) In Moderate-To-Severe Steroid- Refractory Ulcerative Colitis Patients: Real-Life Outcomes In Resource-Constrained Setting At 24-Weeks Follow-Up
}

This article was published in the following Dove Press journal:

Biologics: Targets and Therapy

\section{Alok Chandra \\ Ravi Kanth (D) \\ Sandeep Thareja}

Department of Gastroenterology, Base Hospital, New Delhi, India
Correspondence: Ravi Kanth

Department of Gastroenterology, Base

Hospital, New Delhi, India

Email ravikanthf2@gmail.com
Background: Adalimumab (ADA) is approved for the management of lcerative colitis (UC) not responding to conventional therapy. Use of biologics in resource-constrained settings is very challenging. Currently, real-life data on the safety and efficacy of ADA biosimilar (Exemptia) in steroid-refractory UC patients are limited.

Aim and objectives: To assess the efficacy and safety of ADA biosimilar (Exemptia) to treat steroid-refractory difficult-to-treat UC patients in a resource-constrained Indian setting at 24-weeks follow-up.

Materials and methods: This was a retrospective single-center study to evaluate the efficacy and safety of ADA biosimilar (Exemptia) in steroid-refractory UC patients. All the eligible patients who received induction dose of $160 \mathrm{mg}$ at week $0,80 \mathrm{mg}$ at week 2 and $40 \mathrm{mg}$ at week 4 and $40 \mathrm{mg}$ every 4 weeks as maintenance regimen from 01 September 2017 to 31 Jan 2019 were retrospectively included in this single-center analysis. Those patients who had shown sub-optimal response at 12 weeks received $40 \mathrm{mg}$ every 2 weeks as maintenance therapy. Outcomes in terms of clinical remission, clinical response and mucosal healing were evaluated in the short term at 12 weeks and 24 weeks.

Results: Twenty-five patients were retrospectively included between the time period of 1 September 2017 to 31 July 2018 with a mean age of 35 years. ADA biosimilar was effective in inducing clinical remission in $16 \%$ patients at 12 and 24 weeks, clinical response was seen in $48 \%$ at week 12 and $44 \%$ at week 24 . The mean baseline total Mayo score (TMS) for all patients was 10.16 which decreased to a mean score of 5.72 at 12 weeks and 5.52 at 24 weeks with therapy with the decrease of the score being statistically significant both at 12 and 24 weeks $(p<0.05)$. Two patients (8\%) developed pulmonary tuberculosis (TB). ADA biosimilar frequency was accelerated to once in 2 weeks in 14 (56\%) patients who did not show an optimal response at 12 weeks. Of these 14 patients, 5 were responders and 9 were non-responders at 12 weeks. At 24 weeks, 6 patients showed clinical response and 7 were non-responders, while one patient had developed TB.

Conclusion: ADA biosimilar (Exemptia) therapy is a safe and cost-effective alternative to original biologics in difficult-to-treat UC patients in resource-constrained Indian setting with comparable efficacy. Maintenance therapy at four weekly intervals can be considered in those patients who have shown an early clinical response at 12 weeks to minimize costs, but more studies are needed to confirm the same.

Keywords: ulcerative colitis, steroid refractory, adalimumab, biosimilar, exemptia 


\section{Introduction}

Ulcerative colitis (UC) is a chronic inflammatory disease of the large intestine. Its exact cause is believed to be multi-factorial, with complex interaction between genetic and environmental factors that result in uncontrolled activation of the intestinal mucosal immune system and resulting inflammation that affects the gut mucosa. ${ }^{1,2}$ Initially, treatment strategies focused mainly on the suppression of immune response leading to clinical remission and it had little or no effect on natural disease course. ${ }^{3,4}$ Multiple studies have shown that active mucosal inflammation leads to further mucosal damage and increased risk of colorectal cancer, even if the patients are in clinical remission, so the concept of mucosal healing has come into vogue and has become the current standard of care in UC.,

Tumor necrosis factor-Alfa (TNF- $\alpha$ ) is a pro-inflammatory cytokine that plays a key role in the initiation and amplification of mucosal inflammatory cascade in UC leading to mucosal injury. ${ }^{7} \mathrm{TNF}-\alpha$ antagonists are the main therapeutic option in patients who have not responded adequately to conventional treatment with steroids and immunomodulatory agents. Over the last 15 years, Infliximab (IFX) and ADA have been the main biological therapies used for the treatment of UC, as they have been shown to induce and subsequently maintain both clinical and endoscopic remission. ${ }^{6,8}$ The effectiveness of ADA in the treatment of UC was shown in landmark trials ULTRA 1 and 2. ${ }^{9,10}$ Subsequent to these 2 randomized placebo-controlled trials, multiple real-time studies have also reinforced the efficacy of ADA in moderate-to-severely active UC. ${ }^{11-16}$ ADA has benefits in terms of ease of administration via subcutaneous route, and hospitalization is not required with ADA. Treatment of UC, especially in difficult-to-treat steroid-refractory patients, is always a challenge in developing countries like India. Use of biologics in Inflammatory bowel disease (IBD) in developing countries poses various challenges including higher cost and risk of various infections, especially TB in developing countries. ${ }^{17}$

The relatively high cost of therapy with biological agents and the recent expiry of the patent of some of these biological agents have led to the development of "biosimilar agents", which may be broadly defined as biotherapeutic products with quality, safety, and efficacy that are similar and comparable to the licensed reference biological agents. ${ }^{18}$ Exemptia (ZRC-3197) is the first ADA biosimilar drug that was commercialized by Zydus
Cadila (India) in 2014 and is currently licensed for use in India and Nepal and awaiting approval in other countries. ${ }^{19}$ Exemptia is a fully human-recombinant monoclonal IgG1 antibody having a molecular weight of approximately $148 \mathrm{kDa}$ with 2 copies each of heavy chains and light chains in the heterodimeric form. When evaluated against the originator ADA molecule (Humira) using analysis by cell-based assays and plasma resonance techniques, Exemptia demonstrated similar key structural and functional properties and showed a comparable level of heterogenicity and purity. ${ }^{20}$ Few clinical studies exist on the comparative efficacy of ADA biosimilar (Exemptia) against the original ADA molecule (Humira) and none in patients with IBD. One study comparing efficacy of Exemptia against Humira in patients with Rheumatoid Arthritis demonstrated a high degree of biosimilarity with respect to efficacy, tolerability and safety of test ADA (Exemptia) and the reference ADA (Humira). ${ }^{21}$

In a recent study by Midha et al, ADA biosimilar (Exemptia) showed poor efficacy as salvage therapy in inducing remission at 8 weeks in steroid-refractory active UC patients (those with acute colitis who did not respond to 5 days of therapy with intravenous steroids). ${ }^{22}$ However, another recently published multicenter study from India by Kamat et al, using ADA biosimilar (Exemptia) in IBD patients (including Crohns disease and UC), showed reasonable efficacy and safety at 26 and 52 weeks using simple clinical activity indices to assess response. ${ }^{23}$

In this retrospective study, we report on the real-time effectiveness of ADA biosimilar (Exemptia) in severe UC refractory to steroids at 24-weeks follow-up in a resourceconstrained setting. In India, the use of biologics as therapy has been limited by the high costs that must be borne by patients and the introduction of biosimilars has been a welcome change primarily in view of the cost aspect. We have used once-in-4-week maintenance regimen in those patients who have shown good response to induction therapy with close follow-up/monitoring and scaling up to once in 2 weeks standard maintenance therapy in those with inadequate response at 12 weeks, with the primary aim of reducing the cost of therapy, improving patient compliance and reducing the risk of $\mathrm{TB}$ and other infections.

\section{Aim And Objectives}

The principal aim of this retrospective study was to assess the efficacy and safety of ADA biosimilar (Exemptia) to 
treat steroid-refractory moderate-to-severe UC patients in resource-constrained Indian setting with once a 4-week regimen at 24-weeks follow-up.

\section{Materials And Methods}

This was a retrospective single-center study to evaluate the efficacy and safety of ADA biosimilar (Exemptia) in patients with steroid-refractory moderate-to-severe UC. This study was done from 1 September 2017 to 31 January 2019 and retrospectively included patients with steroid-refractory UC fulfilling inclusion and exclusion criteria who received induction dose of $160 \mathrm{mg}$ at week $0,80 \mathrm{mg}$ at week 2 and $40 \mathrm{mg}$ at week 4 and $40 \mathrm{mg}$ every 4 or 2 weeks as a maintenance regimen. The study was approved by Institutional ethics committee of Base hospital (IEC BHDC/06 of 2017). The entire study was done as per the principles of the Declaration of Helsinki and according to good clinical practice. Written informed consent was taken from all the subjects.

\section{Patients}

A total of 25 patients who met inclusion and exclusion criteria were included in the study.

\section{Inclusion Criteria}

Eligible patients included men and women of at least 18 years of age with an established diagnosis of UC according to standard criteria of European Crohn's \& Colitis guidelines. ${ }^{24}$ All the patients were diagnosed with colonoscopy and histopathology before enrolling into the study. All the patients included in the study had moderate-tosevere UC defined as total Mayo score (TMS) of 6-12 points and Mayo endoscopic sub-score (MESS) $>2$ points in spite of concomitant therapy with immunosuppressive agents. All patients were steroid refractory (defined as those who had active disease despite prednisolone at a dose of $0.75 \mathrm{mg} / \mathrm{kg} /$ day for a period of 04 weeks). Most patients had a relapse while on immunosuppressive therapy with Azathioprine (AZA) and 5-Aminosalicylic acid (5-ASA) at optimal doses requiring repeat therapy with prednisolone and despite the same still had active disease. These steroid-refractory patients were treated with ADA biosimilar.

\section{Exclusion Criteria}

Patients with hepatitis $\mathrm{B}$, hepatitis $\mathrm{C}$, human immunodeficiency virus, indeterminate colitis/Crohn's colitis, Clostridium difficile (CD) infection, TB and cytomegalovirus
(CMV) infection were excluded from the study. Patients were screened for $\mathrm{CD}$ infection by glutamate dehydrogenase and $\mathrm{CD}$ toxin $\mathrm{A} / \mathrm{B}$ test of stool samples. All the patients were screened for TB with chest X-ray, contrast enhanced CT scan, physical examination, tuberculin skin test and interferon- $\gamma$ release assays (QuantiFERON TB gold). Patients with latent $\mathrm{TB}$ (positive tuberculin test or positive interferon- $\gamma$ assay) and those with sequelae of past TB were excluded. All females with childbearing potential were screened for pregnancy by a urine test at baseline and at frequent intervals during the study, and all pregnant females were excluded from the study. Infection with CMV was excluded by blood tests for CMV DNA by PCR and the histopathological examination of biopsy for owl's eye inclusion bodies. Patients with neurological, renal, cardiac diseases, malignancies or any other systemic illness were also excluded.

\section{Study Design}

This was a retrospective study and all the patients included in the study from 01 September 2017 to 31 July 2018 were given ADA biosimilar (Exemptia) induction dose of $160 \mathrm{mg}$ (4 injections of $40 \mathrm{mg}$ each) at week $0,80 \mathrm{mg}$ ( 2 injections of $40 \mathrm{mg}$ ) at week 2 and $40 \mathrm{mg}$ at week 4. All patient data including demographic characteristics, diagnosis, disease duration, past treatment given, past history of $\mathrm{TB}$, duration and frequency of ADA biosimilar, concomitant medications, disease activity scores (TMS and MESS) and adverse events were noted in a standardized format on an Excel sheet.

\section{Diagnosis And Management}

Patients were diagnosed based on colonoscopy and histology as per standard ECCO guidelines, disease extent was assessed as per Montreal classification and severity was evaluated based on Mayo score. ${ }^{24,25}$ After induction therapy at week 0, 2 and 4, all patients were given maintenance dose at $40 \mathrm{mg}$ every 4 weeks till 12 weeks. After 12 weeks, we have used once-in-4-week maintenance regimen in those patients who have shown good response to induction therapy and shortened the maintenance dose interval to 2 weekly in those with inadequate clinical or endoscopic response at 12 weeks, the primary aim being to reduce the cost of therapy with close monitoring for any loss in efficacy, improving patient compliance due to affordability/cost factors and also to reduce the risk of opportunistic infections especially TB which is always a 
threat in Indian setting. The dose of concomitant medications such as 5-ASA and AZA remained constant or was optimized based on clinical factors, and corticosteroids, if being used, were gradually tapered over 4 to 6 weeks. All the patients were evaluated at weeks 12 and 24 for clinical response, calculation of TMS and also underwent colonoscopy to assess mucosal healing and calculation of MESS (Table 1).

\section{Efficacy Evaluation And Endpoints}

The principal objective was to assess for efficacy in terms of clinical outcomes (clinical/endoscopic response and remission) of ADA biosimilar therapy in patients with $\mathrm{UC}$ and the development of any side effects. All patients were monitored for daily stool frequency, the number of bloody stools, abdominal pain and lab tests including complete blood count, ESR, C-reactive protein, liver function tests, albumin, urea/creatinine, electrolytes, and stool examination were done at baseline, 12 weeks and 24 weeks. Clinical remission was defined as TMS of $\leq 2$ points, with no individual score $>1$ point. Decrease in the TMS by at least 3 points from the baseline and decrease in rectal bleeding score by at least 1 point and an absolute rectal bleeding score of 0 or 1 were defined as clinical response. Endoscopic remission was defined as a MESS of $\leq 1$. No response to induction therapy (lack of improvement of clinical signs and symptoms with a decrease of $<3$ points from baseline in TMS) was defined as primary nonresponse. Secondary non-response was defined as an initial response to therapy after induction regimen with subsequent loss of response during remission maintenance treatment.

Clinical assessment during follow-up included monitoring for the occurrence of any adverse events, need of dose escalation in order to obtain/maintain remission and response, and need to discontinue treatment because of any adverse events or primary failure (defined as a failure in reaching remission/clinical response after induction therapy).

\section{Safety Evaluation}

All the patients were closely monitored for any adverse events and infection (eg hepatitis B, hepatitis C, human immunodeficiency virus, Tuberculosis, CMV infection, and other opportunistic infections) during the therapy with ADA biosimilar.

\section{Statistical Analysis}

Statistical analysis was done using Prism software. Descriptive statistics were used. p-Value, mean and standard deviation were calculated. Wherever appropriate, frequency, number, and percentage are mentioned. P-values $<0.05$ were considered significant. One-way ANOVA was used to calculate the p-value at 12- and 24-weeks analysis.

\section{Results}

\section{Baseline Patient Characteristics}

The demographic and baseline characteristics of 25 patients are as shown in Table 2. Patients included those who received induction therapy with ADA biosimilar (Exemptia) between the time period of 1 September 2017 and 31 July 2018.

The mean age was 35 years and $66 \%$ of patients were female while $44 \%$ were male. Biopsy was done for all the subjects at baseline which confirmed UC in the active phase. Twelve patients had pan-colitis while 11 had leftsided colitis and 2 had proctitis. ADA biosimilar was used as therapy in those UC patients who were non-responders to AZA and 5-ASA and did not respond to repeated prednisolone therapy at a dose of $0.75 \mathrm{mg} / \mathrm{kg} /$ day for a period of 04 weeks. Two patients were previously given IFX of which one was a primary non-responder and other had a secondary failure and these patients subsequently received ADA biosimilar therapy. Twenty-three patients (92\%) patients were naive to anti-TNF therapy. All the patients were previously treated with 5-ASA and steroids, while 24

Table I Mayo Scoring System

\begin{tabular}{|l|l|l|l|l|}
\hline Variable & 0 Points & I Points & 2 Points \\
\hline $\begin{array}{l}\text { Bowel Movement (BM) } \\
\text { Frequency }\end{array}$ & Normal & I-2 BM >normal & $3-4$ BM >normal \\
$\begin{array}{l}\text { Rectal Bleeding } \\
\text { Mayo Endoscopy }\end{array}$ & None & $\begin{array}{l}\text { Streaks on stool < 50\% BMs } \\
\text { Sub-score (MESS) }\end{array}$ & $\begin{array}{l}\text { Mild erythema, decreased } \\
\text { vascularity, mild friability }\end{array}$ & $\begin{array}{l}\text { Obvious fresh blood with most BM's } \\
\text { Marked erythema, loss of vascular pattern, } \\
\text { friability, erosions } \\
\text { Assessment }\end{array}$ \\
Mild & $\begin{array}{l}\text { Moderate } \\
\text { ulceration } \\
\text { Severe }\end{array}$ & \\
\hline
\end{tabular}


Table 2 Baseline And Demographic Patient Characteristics

\begin{tabular}{|c|c|}
\hline Characteristic & Value \\
\hline Number of patients & 25 \\
\hline Age & $35.64 \pm 12.58$ \\
\hline Sex Male: Female & $\mathrm{II}: \mid 4$ \\
\hline Male & II (44\%) \\
\hline Female & $14(66 \%)$ \\
\hline \multicolumn{2}{|l|}{ Disease extent } \\
\hline Proctitis (E I) & $2(8 \%)$ \\
\hline Distal colitis (E2) & II (44\%) \\
\hline Pancolitis (E3) & 12 (48\%) \\
\hline \multicolumn{2}{|l|}{ Disease duration } \\
\hline Hemoglobin (g/dL) & $10.1 \pm 1.99$ \\
\hline Albumin (g/dL) & $3.21 \pm 0.39$ \\
\hline ESR & $31 \pm 12.0$ \\
\hline Weight & $55.84 \pm 5.92$ \\
\hline Mayo score, mean & $10.16 \pm 0.90$ \\
\hline \multicolumn{2}{|l|}{ Prior exposure } \\
\hline 5-Aminosalicylates & $25(100 \%)$ \\
\hline Azathioprine & $24(96 \%)$ \\
\hline Corticosteroids & $25(100 \%)$ \\
\hline Infliximab & $2(8 \%)$ \\
\hline
\end{tabular}

patients were treated previously with AZA. Concomitant medications included AZA in 24 (96\%) patients and 5ASA in all the patients.

The average weight of subjects at the baseline was $55.84 \pm 5.92 \mathrm{~kg}$. Mean TMS at baseline was $10.16 \pm$ 0.90 with no significant differences between IFX-naive and IFX-exposed patients. Sixteen (64\%) patients had UC of moderate intensity (TMS of 6-10) while the disease was severe (TMS of 11-12) in $9(36 \%)$ patients. The mean MESS at baseline was $2.8 \pm 0.41$.

The study outline is given in Figure 1. All the patients received an induction dose of ADA biosimilar $160 \mathrm{mg}$ at week $0,80 \mathrm{mg}$ at week 2 and $40 \mathrm{mg}$ at week 4. After that, all the patients were continued on once-in4-week maintenance regimen. At 12-weeks follow-up, 14 patients $(66 \%)$ had their ADA biosimilar dose increased to once every 2 weeks due to a sub-optimal or poor clinical or endoscopic response. The frequency of ADA biosimilar was accelerated either in non-responders or in those patients who had a MESS of more than 2. Of these 14 patients, 9 were non-responders and 5 showed a clinical response at 12 weeks but had a MESS of more than 2 .
Assessed for eligibility $(n=25)$

Allocated to intervention $(n=25)$

$\checkmark$ Received allocated intervention ( $n=25)$

- Did not receive allocated intervention $(n=0)$

\section{2 weeks follow-Up}

Lost to follow-up $(n=0)$

Discontinued intervention $(n=0)$

- Clinical Remission $(n=4)$

- Clinical Response $(n=12)$

- Non Responders $(n=9)$

- Exemptia Once in 4 weeks $(n=11)$

- Exemptia Once in 2 weeks $(n=14)$

(Non responders or Endoscopic subscore $\geq 2$ )

\section{4 weeks follow-Up}

Lost to follow-up ( $n=0)$

Discontinued intervention $(n=0)$

- Clinical Remission $(n=4)$

- Clinical Response $(n=11)$

- Non Responders $(n=8)$

- Tuberculosis $(n=2)$

Figure I Study design in ulcerative colitis patients on ADA biosimilar and reasons for discontinuation.

\section{Clinical Effectiveness}

Clinical remission was achieved in $4(16 \%)$ of 25 patients at week 12 while the clinical response was observed in 12 patients $(48 \%)$ with a total of 16 patients (64\%) showing clinical response and remission at week 12 (Figure 2). The rate of clinical remission at week 24 was the same at $16 \%$ (4 of 25 patients) while 11 (44\%) of 25 patients had shown a clinical response at week 24 (Figure 3). Thus at week 24, a total of clinical response and remission was seen in 15 patients $(60 \%)$. Two patients developed pulmonary TB. No response to therapy was noted in 9 patients (36\%) and 8 patients $(28 \%)$ at weeks 12 and 24, respectively. 


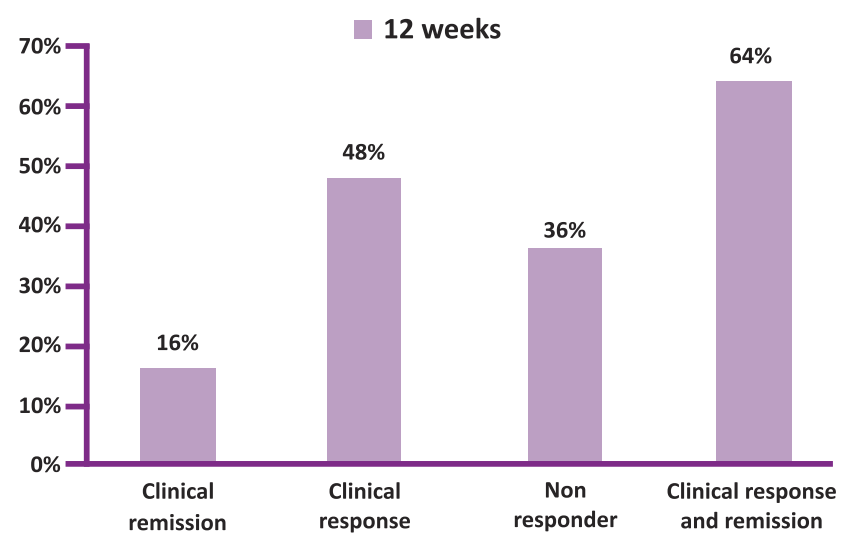

Figure 2 Clinical remission/response at I2-weeks follow-up.

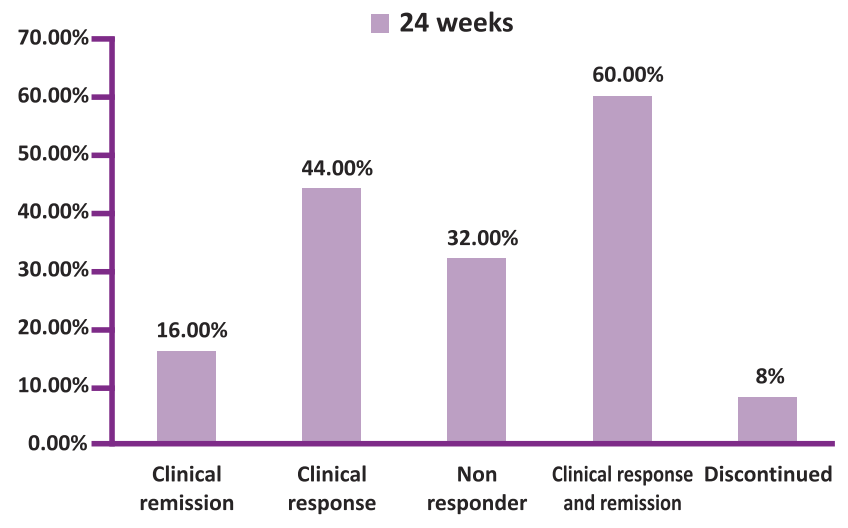

Figure 3 Clinical remission/response at 24-weeks follow-up.

Total Mayo Score (Mean)

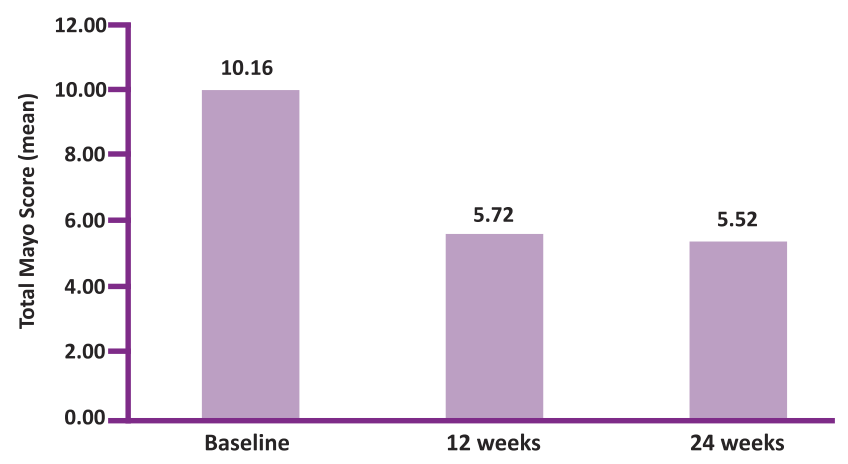

Figure 4 Total Mayo Score (TMS) at Baseline, 12 weeks and 24 weeks ( $\mathrm{N}=25$ at 12 weeks and $\mathrm{N}=23$ at 24 weeks).

Mean values of TMS and MESS are given in Figures 4 and 5. The mean baseline TMS for all patients was 10.16 which decreased to a mean score of 5.72 at 12 weeks and 5.52 at 24 weeks with therapy with the decrease of the score being statistically significant both at 12 and 24 weeks $(\mathrm{p}<0.05)$. The mean MESS at baseline for all patients was 2.8 which corresponded to moderate-to-severe disease
Mayo Endoscopic Subscore (Mean)

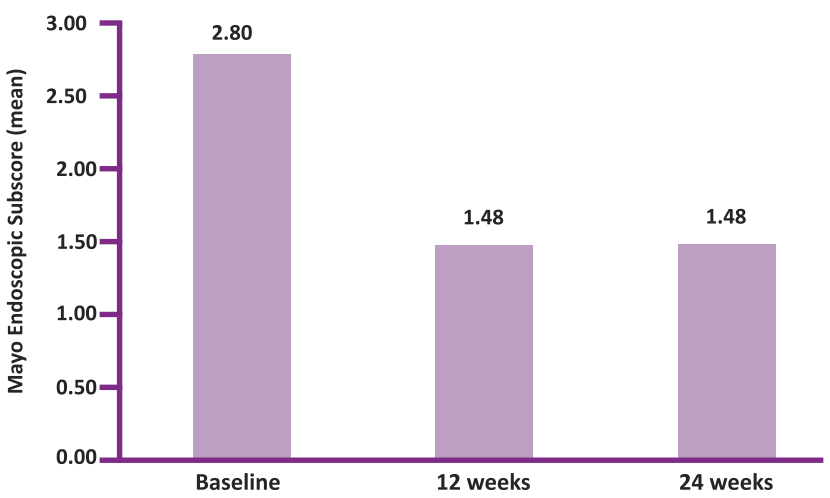

Figure 5 Mayo endoscopic sub-score (MESS) at Baseline, 12 weeks and 24 weeks $(\mathrm{N}=25$ at 12 weeks and $\mathrm{N}=23$ at 24 weeks).

activity while the mean MESS at 12 and 24 weeks was 1.48 with therapy which was significant $(p<0.05)$. Although there was a significant reduction in TMS and MESS from baseline to 12 weeks and 24 weeks with therapy, the reduction from 12 weeks to 24 weeks was non-significant in both TMS and MESS (Table 3).

Sustained clinical remission, defined as clinical remission at week 12 maintained through week 24, was achieved in all the $4(16 \%)$ of 25 patients who achieved remission at 12 weeks. These 4 patients also showed complete mucosal healing (endoscopic sub-score of 0 ) at 12 and 24 weeks. Endoscopic remission (MESS of $<$ _1) was achieved in 11 (44\%) patients at weeks 12 and 24 $(\mathrm{N}=25)$. Of 25 patients, none of the patients required colectomy. No death was reported. Other pharmacological salvage measures including corticosteroids and IFX were used in non-responders.

ADA biosimilar frequency was accelerated to once in 2 weeks in $14(56 \%)$ patients who had sub-optimal clinical or endoscopic response at 12 weeks. Of these 14 patients, 5 were clinical responders and 9 were non-responders at 12 weeks. The 5 patients who were clinical responders,

Table 3 Total Mayo Score (TMS) And Mayo Endoscopic Sub-Score (MESS) At Baseline, 12 Weeks And 24 Weeks ( $N=25$ At 12 Weeks And $\mathrm{N}=23$ At 24 weeks)

\begin{tabular}{|l|l|l|}
\hline & $\begin{array}{l}\text { Total Mayo } \\
\text { Score } \\
\text { Significant } \\
(\mathbf{P}<\mathbf{0 . 0 5})\end{array}$ & $\begin{array}{l}\text { Mayo Endoscopic } \\
\text { Sub-Score } \\
\text { Significant } \\
(\mathbf{P}<\mathbf{0 . 0 5})\end{array}$ \\
\hline $\begin{array}{l}\text { Baseline vs 12 Weeks } \\
\text { Baseline vs 24 Weeks } \\
\text { I2 Weeks vs 24 Weeks }\end{array}$ & $\begin{array}{l}\text { Yes } \\
\text { Yes }\end{array}$ & $\begin{array}{l}\text { Yes } \\
\text { Yes } \\
\text { No }\end{array}$ \\
\hline
\end{tabular}


however, had a MESS of more than 2. Of these 14 patients, 6 patients showed clinical response while 7 were non-responders at 24 weeks and 1 patient developed TB (Table 3). Of 6 responders, MESS decreased by at least 1 point in 2 patients.

\section{Safety Evaluation}

Adverse effects were noted in 2 patients (8\%) with both patients developing TB. One patient developed pulmonary parenchymal TB while the other developed TB pleural effusion. These 2 patients were discontinued from ADA biosimilar therapy and started on anti-TB therapy as per standard guidelines. None of the patients exhibited leucopenia or demyelination during the study.

\section{Discussion}

This is a retrospective single-center study of difficultto-treat steroid-refractory UC patients treated with ADA biosimilar (Exemptia) to assess its short-term efficacy and safety over a period of 24 weeks in inducing clinical/endoscopic response and remission. All the included patients were difficult-to-treat subset with moderate-to-severe steroid-refractory UC having sub-optimal response while on immunomodulatory therapy. Two patients in this study were prior nonresponders to IFX.

Despite difficult-to-treat patient profile, $16 \%$ of patients achieved clinical remission at week 12 with all of them having complete clinical and endoscopic remission. In the landmark ULTRA-1 trial, which first established the safety and efficacy of ADA in moderate-to-severe UC, $18.5 \%$ of patients achieved clinical remission at week $8 .^{9}$

Various studies across the globe have also reported almost similar efficacy of ADA in UC patients. ${ }^{16,26}$ Clinical response at week 12 was $48 \%$ and a total of $64 \%$ patients (including remission) responded to ADA biosimilar treatment. In ULTRA-2 landmark trial, 50.4\% patients had shown a clinical response at week 8 , whereas a prospective real-time Hungarian study by Szepes et al showed remission/response rates of $23.5 \%$ and $52.5 \%$ at week 12 in a similar subset of steroid-refractory patients while another study by Balint et al reported $49.3 \%$ $(\mathrm{N}=73)$ clinical response at week 12 in the Hungarian population. ${ }^{10,27,28}$

In the study by Midha et al, of 29 patients with steroid-refractory active UC treated with ADA biosimilar (Exemptia), clinical response was noted in only 7 patients $(24.5 \%)$ at 8 weeks while $4(14 \%)$ developed active $\mathrm{TB}^{22}$ In our opinion, this variation in clinical response in the study by Midha et al and present study may be due to differences in extent and severity of disease in the selected patient cohort, variation in definition of steroid-refractory active UC, absence of concomitant use of immunomodulatory therapy with AZA and early assessment of response at 8 weeks. In another recent multicenter study by Kamat et al using simple clinical parameters to assess remission, of 21 patients with UC, ADA biosimilar (Exemptia) was able to induce remission in $52.7 \%$ patients at 8 weeks with $33.3 \%$ of patients (three fourth of remitters) maintaining remission at 1 year. $^{23}$ These findings are similar to the current study, wherein $16 \%$ patients had clinical and endoscopic remission while $48 \%$ showed clinical response at 12 weeks.

At 24 weeks, clinical remission was achieved in $16 \%$ patients and clinical response was seen in $44 \%$ with a total of $60 \%$ patients responding to therapy. Afif et al, in 2009 , reported $20 \%$ and $50 \%$ clinical remission and response at week 24 in US population $(\mathrm{N}=20)$ while an Italian study by Armuzzi et al reported higher clinical remission rates of $36.4 \%$ at week 24. ${ }^{11,16}$ The strict criteria (MESS less than 1 and TMS <3) use of a biosimilar instead of originator ADA and difficult-to-treat steroid-refractory population in the current study might be the reason for slightly less remission as compared to other real-world observational studies. $^{11,27-29}$

In the current study, a significant reduction in TMS and MESS from baseline to 12 weeks and 24 weeks was observed. Although a reduction from 12 weeks to 24 weeks was non-significant in both TMS and MESS, endoscopic remission was achieved in $44 \%$ (MESS of $\leq 1$ ) patients at 12 and 24 weeks. Complete mucosal healing was achieved in $16 \%$ patients at 12 and 24 weeks (endoscopic sub-score of 0 ). Complete mucosal healing in the current study was higher than in the Italian study by Armuzzi et al. ${ }^{16}$

ADA biosimilar has also shown efficacy as a steroidsparing drug in this patient population. Steroids were withdrawn in all the patients who showed clinical response and remission while 5-ASA and AZA were continued at optimal doses. Steroid-free remission/ response was achieved in $60 \%$ of patients at 24 weeks which is comparatively higher than the steroid-free remission achieved in the Italian study (40\% at 1 year). ${ }^{16}$ No patient underwent colectomy in this current study. 
Table 4 Total Mayo Score (TMS) And Mayo Endoscopic Sub-Score (MESS) Of 14 Patients Whose Dose Has Been Accelerated At 12 Weeks From Once In 4 Weeks To Once In 2 Weeks

\begin{tabular}{|l|l|l|l|}
\hline & Baseline & 12 Weeks & 24 Weeks \\
\hline $\begin{array}{l}\text { Total Mayo Score } \\
\text { (Mean) }\end{array}$ & $10.29 \pm 0.6 \mathrm{I}$ & $7.86 \pm 1.29$ & $7.46 \pm 2.44$ \\
Mayo Endoscopic & $2.93 \pm 0.27$ & $2.14 \pm 0.36$ & $2.08 \pm 0.64$ \\
Sub-Score (Mean) & & & \\
Clinical Response & & 5 & 6 \\
Non-Responders & & 9 & 7 \\
Adverse Events (TB) & & 0 & 1 \\
\hline
\end{tabular}

This is comparable to a previous real-world study using ADA by Afif et al in 2009 that reported no colectomy in US population $(\mathrm{N}=20)$, while another study by Balint et al reported colectomy in $5.4 \%$ patients in Hungarian population $(\mathrm{N}=73) \cdot{ }^{11,28}$

ADA biosimilar frequency was maintained at once in 4 weeks in $11(44 \%)$ patients. Of these 11 patients, 4 were in clinical remission, 5 showed clinical response whereas 1 patient developed TB and 1 patient was nonresponder at 24 weeks. This suggests that those patients with good early response post-induction therapy are likely to maintain response even with 4-weekly maintenance dose frequency. ADA biosimilar frequency was accelerated to once in 2 weeks in $14(56 \%)$ patients at 12 weeks. Of these 14 patients, 5 were responders but had MESS of more than 2 while 9 were non-responders at 12 weeks. At 24 weeks, 6 patients showed clinical response with a mild decrease in cumulative MESS while 7 were non-responders and one patient developed TB (Table 4). Of 5 responders who had a MESS of more than 2 at 12 weeks, MESS decreased by 1 point in two patients at 24 weeks. However, the overall reduction was non-significant in both TMS and MESS from 12 weeks to 24 weeks.

In the present study, of 25 patients, only 2 patients (8\%) developed side effects with both patients developing TB. In the study by Kamat et al, of total 70 patients with Crohns and UC, $28.6 \%$ patients experienced adverse effects with 7 patients (10\%) having serious adverse events and 3 patients developed TB. ${ }^{23}$ In the study by Jani et al, both Exemptia and Humira were safe and well tolerated, while in the study by Midha et al, of 29 patients, 4 patients developed TB at 8 weeks. ${ }^{21,22}$ The use of longer dosing interval of 4-weekly maintenance therapy in our study in comparison to recommended 2-weekly dosing interval may have contributed to lesser incidence of adverse events due to TB.

Apart from the efficacy of the drug, the cost of drug always matters in resource-constrained settings to maintain long-term remission. In the current study, $44 \%$ of patients remained on once-in-4-week therapy with good clinical response of which $16 \%$ showed sustained clinical remission at 24 weeks. This lesser frequency of biologic therapy will be economical and cost-effective when compared to different previous western studies using ADA (Table 5). No requirement of colectomy and lesser side effects further strengthen the role of ADA biosimilar as a costeffective alternative in difficult-to-treat steroid-refractory UC patients.

\section{Conclusion}

ADA biosimilar (Exemptia) therapy is a safe and costeffective alternative to original biologics in difficult-totreat UC patients in resource-constrained Indian setting with comparable efficacy. Maintenance therapy at four weekly intervals can be considered in those patients who have shown an early clinical response at 12 weeks to

Table 5 Various Reported Real-Time Studies On Adalimumab In UC

\begin{tabular}{|c|c|c|c|c|c|c|c|c|}
\hline S.No & Study & Country & $\mathbf{N}$ & $\begin{array}{l}\text { Clinical } \\
\text { Remission } \\
\text { (1 } 2 \text { Weeks) }\end{array}$ & $\begin{array}{l}\text { Clinical } \\
\text { Response } \\
\text { (1 } 2 \text { Weeks) }\end{array}$ & $\begin{array}{l}\text { Clinical } \\
\text { Remission } \\
\text { (24 Weeks) }\end{array}$ & $\begin{array}{l}\text { Clinical } \\
\text { Response } \\
\text { (24 Weeks) }\end{array}$ & Colectomy \\
\hline I & Current study & India & 25 & $16 \%$ & $48 \%$ & $16 \%$ & $44 \%$ & 0 \\
\hline 2 & Taxonera et al, $201 \mathrm{I}^{15}$ & Spain & 30 & $26.7 \%$ & $60 \%$ & - & - & $20 \%$ \\
\hline 3 & Balint et al, $2016^{28}$ & Hungary & 73 & $26 \%$ & $49.3 \%$ & - & - & $5.4 \%$ \\
\hline 4 & Afif et al, $2009^{\prime \prime}$ & USA & 20 & $\begin{array}{l}5 \% \\
\text { (8 weeks) }\end{array}$ & $\begin{array}{l}25 \% \\
\text { (8 weeks) }\end{array}$ & $20 \%$ & $50 \%$ & 0 \\
\hline 5 & Armuzzi et al, $2013^{16}$ & Italy & 88 & $23.4 \%$ & & $36.4 \%$ & & $25 \%$ \\
\hline 6 & Szepes et al, $2014^{27}$ & Hungary & 56 & $23.2 \%$ & $52 \%$ & $\begin{array}{l}54.5 \% \\
\text { (30 weeks) }\end{array}$ & $\begin{array}{l}27.5 \% \\
\text { (30 weeks) }\end{array}$ & - \\
\hline
\end{tabular}


minimize costs, but more studies are needed to confirm the same.

\section{Disclosure}

The authors report no conflicts of interest in this work.

\section{References}

1. Solberg IC, Lygren I, Jahnsen J, et al. Clinical course during the first 10 years of ulcerative colitis: results from a population-based inception cohort (IBSEN Study). Scand J Gastroenterol. 2009;44:431-440. doi:10.1080/00365520802600961

2. Solberg IC, Vatn MH, Høie O, et al. Clinical course in crohn's disease: results of a Norwegian population-based ten-year follow-up study. Clin Gastroenterol Hepatol. 2007;5:1430-1438. doi:10.1016/j. cgh.2007.09.002

3. Bernstein CN, Loftus EV Jr, Ng SC, Lakatos PL, Moum B. Epidemiology and natural history task force of the International Organization for the Study of Inflammatory Bowel Disease (IOIBD) hospitalizations and surgery in Crohn's disease. Gut. 2012;61(4):622-629. doi:10.1136/gutjnl-2011-301397

4. Magro F, Rodrigues A, Vieira AI, et al. Review of the disease course among adult ulcerative colitis population-based longitudinal cohorts. Inflamm Bowel Dis. 2012;18:573-583. doi:10.1002/ibd.21 815

5. Rutgeerts P, D'Haens G, Targan S, et al. Efficacy and safety of retreatment with anti-tumor necrosis factor antibody (infliximab) to maintain remission in Crohn's disease. Gastroenterology. 1999;117:761-769. doi:10.1016/S0016-5085(99)70332-X

6. Rutgeerts P, Sandborn WJ, Feagan BG, et al. Infliximab for induction and maintenance therapy for ulcerative colitis. $N$ Engl $\mathrm{J} \mathrm{Med}$. 2005;353:2462-2476. doi:10.1056/NEJMoa050516

7. Danese S, Angelucci E, Malesci A, Caprilli R. Biological agents for ulcerative colitis: hypes and hopes. Med Res Rev. 2008;28:201-218. doi:10.1002/(ISSN)1098-1128

8. Peyrin-Biroulet L, Laclotte C, Roblin X, Bigard MA. Adalimumab induction therapy for ulcerative colitis with intolerance or lost response to infliximab: an open-label study. World J Gastroenterol. 2007;13:2328-2332. doi:10.3748/wjg.v13.i16.2328

9. Reinisch W, Sandborn WJ, Hommes DW, et al. Adalimumab for induction of clinical remission in moderately to severely active ulcerative colitis: results of a randomized controlled trial. Gut. 2011;60:780-787. doi:10.1136/gut.2010.221127

10. Sandborn WJ, van Assche G, Reinisch W, et al. Adalimumab induces and maintains clinical remission in patients with moderate-to-severe ulcerative colitis. Gastroenterology. 2012;142:257-265. doi:10.1053/ j.gastro.2011.10.032

11. Afif W, Leighton JA, Hanauer SB, et al. An open-label study of Adalimumab in patients with ulcerative colitis including those with prior loss of response or intolerance to infliximab. Inflamm Bowel Dis. 2009;15:1302-1307. doi:10.1002/ibd.20924

12. Trinder MW, Lawrance IC. Efficacy of Adalimumab for the management of inflammatory bowel disease in the clinical setting. $J$ Gastroenterol Hepatol. 2009;24:1252-1257. doi:10.1111/jgh.2009.24. issue-7

13. García-Bosch O, Gisbert JP, Canas-Ventura A, et al. Observational study on the efficacy of Adalimumab for the treatment of ulcerative colitis and predictors of outcome. J Crohns Colitis. 2013;7:717-722. doi:10.1016/j.crohns.2012.10.004

14. Gies N, Kroeker KI, Wong K, Fedorak RN. Treatment of ulcerative colitis with Adalimumab or infliximab: long-term follow-up of a single-center cohort. Aliment Pharmacol Ther. 2010;32:522-528. doi:10.1111/j.1365-2036.2010.04380.x
15. Taxonera C, Estelle J, Fernandez-Blanco I, et al. Adalimumab induction and maintenance therapy for patients with ulcerative colitis previously treated with infliximab. Aliment Pharmacol Ther. 2011;33:340-348. doi:10.1111/apt.2010.33.issue-3

16. Armuzzi A, Biancone L, Daperno M, et al. P230 Adalimumab in active ulcerative colitis: a "real-life" observational study. J Crohns Colitis. 2012;6(Suppl 1):S101-S101. doi:10.1016/S1873-9946(12) 60250-5

17. Cantini F, Niccoli L, Goletti D. Adalimumab, etanercept, infliximab, and the risk of tuberculosis: data from clinical trials, national registries, and post-marketing surveillance. $J$ Rheumatol Suppl. 2014;91:47-55. doi:10.3899/jrheum.140102

18. World Health Organization. Expert committee on biological standardization. In: Guidelines on Evaluation of Similar Biotherapeutic Products. Available from: http://www.who.int/biologicals/areas/biolo gical_therapeutics/BIOTHERAPEUTICS_FOR_WEB 22APRIL2010.pdf. Accessed september 23, 2009.

19. Adalimumab biosimilar; autoimmune disorders; rheumatoid arthritis; juvenile idiopathic arthritis, psoriatic arthritis, ankylosing spondylitis. Exemptia; 2019. Available from: https://exemptia.com/zydus-launchesworlds-first-biosimilar-of-adalimumab. Accessed January 5, 2019.

20. Bandyopadhyay S, Mahajan M, Mehta T, et al. Physicochemical and functional characterization of a biosimilar Adalimumab ZRC-3197. Biosimilars. 2015;5:1-18.

21. Jani RH, Gupta R, Bhatia G, et al. A prospective, randomized, doubleblind, multi-center, parallel-group, active controlled study to compare efficacy and safety of biosimilar Adalimumab (Exemptia; ZRC-3197) and Adalimumab (Humira) in patients with rheumatoid arthritis. Int $J$ Rheum Dis. 2016;19:1157-1168. doi:10.1111/1756-185X.12711

22. Midha V, Mahajan R, Mehta V, et al. Efficacy and safety of the adalimumab biosimilar Exemptia as induction therapy in moderate to severe ulcerative colitis. Intest Res. 2018;16:83-89. doi:10.5217/ ir.2018.16.1.83

23. Kamat N, Kedia S, Ghoshal UC, et al. Effectiveness and safety of adalimumab biosimilar in inflammatory bowel disease: a multicenter study. Indian J Gastroenterol. 2019;38(1):44-54. doi:10.1007/ s12664-018-0922-1

24. Maaser C, Sturm A, Vavricka SR, et al. ECCO-ESGAR guidelines for diagnostic assessment in IBD Part 1: initial diagnosis, monitoring of known IBD, detection of complications. J Crohns Colitis. 2019;13 (2):144-164.

25. Silverberg MS, Satsangi J, Ahmad T, et al. Toward an integrated clinical, molecular and serological classification of inflammatory bowel disease: report of a working party of the 2005 Montreal World Congress of Gastroenterology. Can J Gastroenterol. 2005;19 (Suppl A):5A-36A. doi:10.1155/2005/269076

26. Christensen KR, Steenholdt C, Brynskov J. Clinical outcome of Adalimumab therapy in patients with ulcerative colitis previously treated with Infliximab: a Danish single-center cohort study. Scand J Gastroenterol. 2015;50(8):1018-1024. doi:10.3109/00365521.2015.1019 558

27. Szepes Z, Bálint A, Szücs M, et al. Short and medium-term efficacy of Adalimumab in ulcerative colitis - a multi center, prospective observational study. J Crohn's Colitis. 2014;8(1):S208. doi:10.1016/ S1873-9946(14)60464-5

28. Bálint A, Farkas K, Palatka K, et al. Efficacy and safety of adalimumab in ulcerative colitis refractory to conventional therapy in routine clinical practice. J Crohns Colitis. 2016;10(1):26-30. doi:10.1093/ ecco-jcc/jjv169

29. Tursi A, Elisei W, Faggiani R, et al. Effectiveness and safety of Adalimumab to treat outpatient ulcerative colitis: a real-life multicenter, observational study in primary inflammatory bowel disease centers. Medicine (Baltimore). 2018;97(34):e11897. doi:10.1097/ MD.0000000000011897 


\section{Publish your work in this journal}

Biologics: Targets and Therapy is an international, peer-reviewed journal focusing on the patho-physiological rationale for and clinical application of Biologic agents in the management of autoimmune diseases, cancers or other pathologies where a molecular target can be identified. This journal is indexed on PubMed Central, CAS, EMBase,
Scopus and the Elsevier Bibliographic databases. The manuscript management system is completely online and includes a very quick and fair peer-review system, which is all easy to use. Visit $\mathrm{http} / / / \mathrm{www}$.dovepress.com/testimonials.php to read real quotes from published authors.

Submit your manuscript here: https://www.dovepress.com/biologics-targets-and-therapy-journal 